\title{
Ciliary neurotrophic factor-treated astrocyte-conditioned medium increases the intracellular free calcium concentration in rat cortical neurons
}

\author{
MEIQUN SUN ${ }^{1,2}$, HONGLI LIU ${ }^{3}$, SHENGPING MIN $^{1}$, HONGTAO WANG $^{4}$ and XIAOJING WANG ${ }^{1}$ \\ ${ }^{1}$ Anhui Clinical and Preclinical Key Laboratory of Respiratory Disease, The First Affiliated Hospital of \\ Bengbu Medical College; ${ }^{2}$ Department of Histology and Embryology, Bengbu Medical College; \\ ${ }^{3}$ Department of Gynecological Oncology, The First Affiliated Hospital of Bengbu Medical College; \\ ${ }^{4}$ Department of Immunology, Bengbu Medical College, Bengbu, Anhui 233030, P.R. China
}

Received November 13, 2015; Accepted February 3, 2016

DOI: 10.3892/br.2016.602

\begin{abstract}
Ciliary neurotrophic factor (CNTF) is involved in the activation of astrocytes. A previous study showed that CNTF-treated astrocyte-conditioned medium (CNTF-ACM) contributed to the increase of the calcium current and the elevation of corresponding ion channels in cortical neurons. On this basis, it is reasonable to assume that CNTF-ACM may increase the intracellular free calcium concentration $\left(\left[\mathrm{Ca}^{2+}\right]_{\mathrm{i}}\right)$ in neurons. In the present study, the effects of CNTF-ACM on $\left[\mathrm{Ca}^{2+}\right]_{\mathrm{i}}$ in rat cortical neurons were determined, and on this basis, the aim was to investigate the potential active ingredients in ACM that are responsible for this biological process. As expected, the data indicated that CNTF-ACM resulted in a clear elevation of $\left[\mathrm{Ca}^{2+}\right]_{\mathrm{i}}$ in neurons. Additionally, the fibroblast growth factor-2 (FGF-2) contained in the CNTF-ACM was found to participate in the upregulation of $\left[\mathrm{Ca}^{2+}\right]_{i}$. Taken together, CNTF induces the production of active factors (at least including FGF-2) released from astrocytes, which finally potentiate the increase of $\left[\mathrm{Ca}^{2+}\right]_{\mathrm{i}}$ in cortical neurons.
\end{abstract}

\section{Introduction}

Ciliary neurotrophic factor (CNTF), a survival factor for chick ciliary neurons (1), is reported to facilitate the survival of several types of neurons such as sympathetic, sensory and motor neurons (2). In addition, it has important roles in triggering neurite outgrowth, preventing neuronal degeneration and attenuating motor deficits (3). Recent evidence suggests

Correspondence to: Dr Xiaojing Wang, Anhui Clinical and Preclinical Key Laboratory of Respiratory Disease, The First Affiliated Hospital of Bengbu Medical College, 287 Changhuai Road, Bengbu, Anhui 233030, P.R. China

E-mail: wangxiaojing8888@163.com

Key words: ciliary neurotrophic factor, astrocyte-conditioned medium, intracellular calcium concentration, nerve growth factor, fibroblast growth factor-2 that CNTF is a potential activator of astrocytes, as it could induce astrocyte hypertrophy and glial fibrillary acidic protein (GFAP) overexpression $(4,5)$, which is considered as a predominant feature for the activation of astrocytes.

Astrocytes constitute the majority of the central nervous system (CNS), particularly in the brain. Bidirectional communication has been reported between astrocytes and neurons. On this basis, it is reasonable to speculate that astrocytes may respond to the neuronal activity and be involved in the regulation of neuron activity. Our previous study showed that CNTF-treated astrocyte-conditioned medium (CNTF-ACM) contributed to the elevation of the calcium current and the expression of ion channels in cortical neurons (6). Due to the increase of intracellular free calcium concentration $\left(\left[\mathrm{Ca}^{2+}\right]_{\mathrm{i}}\right)$ preferentially induced by calcium influx mediated by calcium currents, we hypothesize that CNTF-ACM may affect the $\left[\mathrm{Ca}^{2+}\right]_{\mathrm{i}}$ in neurons.

The present study aimed to evaluate the effects of $\mathrm{CNTF}-\mathrm{ACM}$ on the $\left[\mathrm{Ca}^{2+}\right]_{\mathrm{i}}$ in cortical neurons in rats. Astrocytes can secrete several types of factors, such as nerve growth factor (NGF) $(7,8)$ and fibroblast growth factor-2 (FGF-2). FGF-2 $(9,10)$ and NGF $(11,12)$ contribute to the expression of functional calcium channels. In addition, the concentrations of FGF-2 and NGF were determined in CNTF-ACM, as well as its roles in the regulation of $\left[\mathrm{Ca}^{2+}\right]_{\mathrm{i}}$ levels in neurons.

\section{Materials and methods}

Astrocyte culture and collection of ACM. Pregnant Sprague-Dawley rats were obtained from the Experimental Animal Center of Zhejiang Province (Zhengjiang, China). Sprague-Dawley rats (1-2-day-old, $n=20)$ were used for the preparation of cortical astrocytes according to a previous study (13). In brief, following dissociation, the cortical tissue was plated on $75-\mathrm{cm}^{2}$ poly-d-lysine-coated culture flasks in Dulbecco's modified Eagle's medium (DMEM)/F12 (1:1) supplemented with $100 \mu \mathrm{g} / \mathrm{ml}$ streptomycin, $100 \mathrm{U} / \mathrm{ml}$ penicillin and $10 \%$ fetal bovine serum (Gibco, Thermo Fisher Scientific, Inc., Waltham, MA, USA). The cultures were maintained in a humid incubator at $37^{\circ} \mathrm{C}$ in $5 \% \mathrm{CO}_{2}$. After confluence at 7-10 days in vitro (DIV), the cells were agitated at $37^{\circ} \mathrm{C}$ at $250 \mathrm{rpm}$ for 
15-18 h for subculture. The yield of astrocytes was $>95 \%$, as revealed by immunostaining glial fibrillary acidic protein (GFAP; Santa Cruz Biotechology, Inc., Santa Cruz, CA, USA). Subsequently, the astrocytes were treated with $50 \mathrm{ng} / \mathrm{ml}$ CNTF (PeproTechec, London, UK) for $48 \mathrm{~h}$. Subsequent to rinsing with phosphate-buffered saline (PBS) 3 times, the cells were incubated in fresh serum-free DMEM medium ( $9 \mathrm{ml} / \mathrm{flask}$ ) for $48 \mathrm{~h}$. Following this, the CNTF-ACM was collected, centrifuged at $1,200 \mathrm{x} g$ for $10 \mathrm{~min}$, and filtered through a $0.2-\mu \mathrm{m}$ filter. The untreated ACM (UT-ACM) served as the control. Finally, the samples were stored at $-70^{\circ} \mathrm{C}$ until required for further analysis.

Immunoassay. Levels of FGF-2 and NGF in the CM were determined using commercial enzyme-linked immunosorbent assay (ELISA) kits (R\&D Systems Europe, Abingdon, UK) according to the manufacturer's protocol. The tests were performed at least in triplicate.

Cortical neuron culture and its treatment. For the cell culture, the mixed cells were cultured using the same procedures for astrocytes for $24 \mathrm{~h}$. Following this, the medium was replaced with neurobasal medium supplemented with $2 \%$ B27 supplement, $0.5 \mathrm{mM}$ L-glutamine $1 \%$ antibiotic-antifungal mixture (all from Invitrogen, Carlsbad, CA, USA). At 3 DIV, $5 \mu \mathrm{M}$ arabinosylcytosine $\mathrm{C}$ (Invitrogen) was used to inhibit the growth of glia, followed by culturing at $37^{\circ} \mathrm{C}$ for $24 \mathrm{~h}$ to maximize the percentage of neurons. Subsequently, the medium was replaced by fresh medium to terminate the action of arabinosylcytosine $\mathrm{C}$. At 7-10 DIV, a purity of $95 \%$ was observed by immunostaining neuron-specific enolase (NSE; Santa Cruz Biotechnology, Inc.). Finally, the $\left[\mathrm{Ca}^{2+}\right]_{\mathrm{i}}$ in the neurons was determined following treatment with UT-ACM, CNTF-ACM or CNTF-ACM containing $20 \mathrm{ng} / \mathrm{ml}$ of anti-rat FGF-2 monoclonal neutralizing antibody ( $\alpha$ FGF-2; cat. no. MAB233; R\&D Systems Europe) for $48 \mathrm{~h}$.

Measurement of $\left[\mathrm{Ca}^{2+}\right]_{i}$. To measure the level of $\left[\mathrm{Ca}^{2+}\right]_{\mathrm{i}}$, cortical neurons were loaded for $45 \mathrm{~min}$ at $37^{\circ} \mathrm{C}$ in $10 \mu \mathrm{M}$ fura-2/acetoxymethyl ester in $\mathrm{N}$-(2-hydroxyethyl) piperazine-N'-2-ethanesulfonic acid (HEPES)-buffered Hank's balanced salt solution (20 mM HEPES, $137 \mathrm{mM} \mathrm{NaCl}, 1.3 \mathrm{mM}$ $\mathrm{CaCl}_{2}, 0.4 \mathrm{mM} \mathrm{MgSO}, 0.5 \mathrm{mM} \mathrm{MgCl}{ }_{2}, 0.4 \mathrm{mM} \mathrm{KH}_{2} \mathrm{PO}_{4}$, $0.6 \mathrm{mM} \mathrm{Na} \mathrm{H}_{2} \mathrm{PO}_{4}, 3.0 \mathrm{mM} \mathrm{NaHCO}$ and $5.6 \mathrm{mM}$ glucose) containing $0.5 \%$ bovine serum albumin. LAMBDA DG-4 (Sutter Company, Novato, CA USA) was used to measure the cytosolic calcium in UT-ACM- and CNTF-ACM-treated cortical neurons. Fluorescence intensities were recorded at excitation wavelengths of 340 and $380 \mathrm{~nm}$, and an emission wavelength of $510 \mathrm{~nm}$. Fluorescent signals at excitation wavelengths of 340 and $380 \mathrm{~nm}$ were analyzed. The fluorescence intensity ratio $(\mathrm{R})$ was calculated by the formula of $\mathrm{F}_{340} / \mathrm{F}_{380}$. The level of cytosolic calcium was measured with the formula of $\left[\mathrm{Ca}^{2+}\right]_{\mathrm{i}}=\mathrm{b} \times \mathrm{K}_{\mathrm{d}} \mathrm{x}\left(\mathrm{R}-\mathrm{R}_{\min }\right) /\left(\mathrm{R}_{\max }-\mathrm{R}\right)$ according to a previous study (14), where $\mathrm{Kd}$ is the dissociation constant for fura-2 $(224 \mathrm{nM})$ and $\mathrm{b}$ is the ratio of the fluorescence of fura- 2 at 380 $\mathrm{nm}$ excitation in the presence of minimum calcium and saturating calcium.

Statistical analysis. SPSS 11.5 (SPSS, Inc., Chicago, IL, USA) software was used for the data analysis. Two-way analysis of variance and two-tailed Student's t-test were used for the inter-group comparison. $\mathrm{P}<0.05$ was considered to indicate a statistically significant difference. All the data are expressed as mean \pm standard error of mean.

\section{Results}

Analysis of the levels of calcium in the different treatment medium. The mixed glial cultured from cerebral cortices of neonatal rat were purified to $>95 \%$ astrocytes (Fig. 1A) or neurons (Fig. 1B), as determined by immunostaining with an antibody against GFAP or NSE, respectively. The neurons were incubated with UT-ACM or CNTF-ACM for $48 \mathrm{~h}$, and the cytosolic digital calcium imaging was performed to test the influence of CNTF-ACM on $\left[\mathrm{Ca}^{2+}\right]_{i}$ in neurons. CNTF-ACM resulted in significant induction of fluorescence intensity in neurons compared to that of UT-ACM. The cytosolic free $\mathrm{Ca}^{2+}$ concentrations were $67 \pm 7 \mathrm{nmol} / 1$ in neurons treated with UT-ACM and $213 \pm 17 \mathrm{nmol} / 1$ in neurons treated with CNTF-ACM, respectively (Fig. 2). Compared with the control group, the level of cytosolic free $\mathrm{Ca}^{2+}$ was clearly elevated in the CNTF-ACM $(\mathrm{P}<0.01)$.

Concentrations of FGF-2 and NGF in the different treatment medium. In addition, these factors could augment the amplitude of calcium currents in neurons. To investigate which component in CNTF-ACM is involved in the upregulation of $\left[\mathrm{Ca}^{2+}\right]_{\mathrm{i}}$ in neurons, the concentrations of FGF-2 and NGF were determined in the CM using the ELISA assay. The concentration of FGF-2 showed clear elevation in the CNTF-ACM compared with the UT-ACM (Fig. 3). However, no statistical changes were observed in the level of NGF in the CNTF-ACM compared with the UT-ACM. Based on these findings, FGF-2 may be involved in the upregulation of $\left[\mathrm{Ca}^{2+}\right]_{i}$, as mediated by CNTF-ACM in neurons.

Assessing the effects of FGF-2 on neurons in CNTF-AMC. Following this, $20 \mathrm{ng} / \mathrm{ml} \alpha \mathrm{FGF}-2$ was used to attenuate the potential effects of FGF-2 on neurons in CNTF-AMC. Subsequent to treatment with CNTF-ACM (containing $\alpha$ FGF-2) for $48 \mathrm{~h},\left[\mathrm{Ca}^{2+}\right]_{\mathrm{i}}$ in the cortical neurons was measured. The level of $\left[\mathrm{Ca}^{2+}\right]_{\mathrm{i}}$ in neurons was lower than that treated with CNTF-ACM $(152 \pm 11$ vs. $213 \pm 17 \mathrm{nmol} / \mathrm{l}$; $\mathrm{P}<0.05)$. However, the level was higher than that in the neurons treated with UT-ACM (152 \pm 11 vs. $67 \pm 7 \mathrm{nmol} / \mathrm{l} ; \mathrm{P}<0.05)$ (Fig. 2).

\section{Discussion}

Astrocytes are capable of secreting abundant neuroactive substances, such as neurotransmitters, cytokines and metabolites, which regulate the neuronal activity by direct binding to the receptors and ion channels in neurons (15). ACM, a liquid medium with soluble substances released from astrocytes, constructs a microenvironment that supports certain astrocyte-neuron interaction. Notably, the effects of astrocytes on neurons may be mimicked partially by exposing neurons to $\mathrm{ACM}$ in vitro. For example, ACM is involved in the protection of neurons against damage and contributes to the survival of neurons $(16,17)$. Thus, ACM is an efficacious medium to study the biological roles of astrocytes in modulating the activity of neurons. 


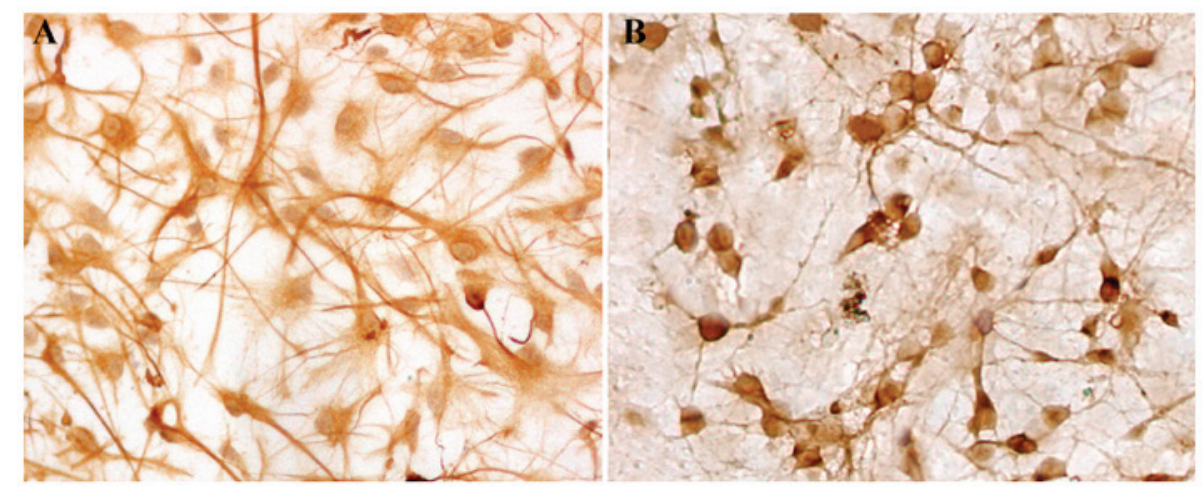

Figure 1. Identification of astrocytes and neurons. (A) Immunostaining against glial fibrillary acidic protein, an astrocyte-specific marker, in primary cultured astrocytes from the rat cortex. (B) Immunostaining against neuron-specific enolase, a neuron-specific marker, in primary cultured neurons from the rat cortex.

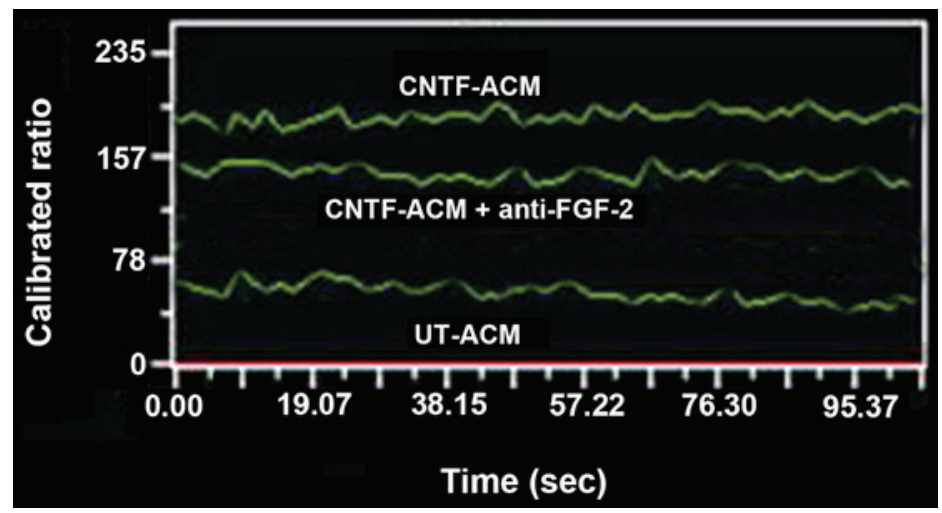

Figure 2. Cytosolic calcium imaging was performed using Fura-2/acetoxymethyl ester to measure the $\left[\mathrm{Ca}^{2+}\right]_{\mathrm{i}}$ in rat cortical neurons treated with UT-ACM, CNTF-ACM or CNTF-ACM + anti-FGF-2, respectively. The level of $\left[\mathrm{Ca}^{2+}\right]_{i}$ was relatively low in the UT-ACM group, compared to those in the CNTF-ACM or CNTF-ACM + anti-FGF-2 group. Data are expressed as mean \pm standard error of the mean of three independent experiments. $\left[\mathrm{Ca}^{2+}\right]_{\mathrm{i}}$, intracellular free calcium concentration; UT, untreated; CNTF, ciliary neurotrophic factor; ACM, astrocyte-conditioned medium; FGF-2, fibroblast growth factor-2.

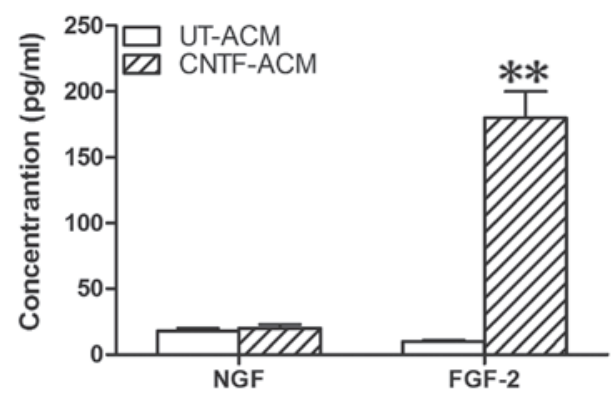

Figure 3. Quantification of NGF or FGF-2 by the ELISA assay. Astrocytes were treated with ciliary neurotrophic factor (CNTF) $(50 \mathrm{ng} / \mathrm{ml})$ or vehicle for $48 \mathrm{~h}$, and the cultured media were collected for NGF or FGF-2 analysis Values are the mean \pm standard error of the mean of three independent experiments. ${ }^{* *} \mathrm{P}<0.001$ as compared with UT-ACM (Student's t-test). NGF, nerve growth factor; FGF-2, fibroblast growth factor-2; UT, untreated; CNTF, ciliary neurotrophic factor; ACM, astrocyte-conditioned medium; ELISA, enzyme-linked immunosorbent assay.

CNTF is a member of the interleukin-6 (IL-6) family, which is mainly synthesized by astrocytes in the CNS. In physiological status terms, the levels of CNTF and its receptor are extremely low in brain parenchyma. However, significant elevation is noticeable in their expression in the presence of brain injury $(18,19)$. Therefore, CNTF is considered to have important roles in coordinating the cellular response to insult in the CNS. As is well-known, the biological functions of CNTF are mediated by a tripartite receptor complex constituted by a nonsignaling subunit (CNTFR $\alpha)$ and two signaling subunits [i.e. gp130 and leukemia inhibitory factor receptor $\beta$ (LIFR $\beta$ )]. The CNTFR $\alpha$ is exclusively expressed in neurons (20), while the CNTF functional receptors (gp130 and LIFR $\beta$ ) are mainly detected in astrocytes. This suggests that these factors may serve as an action target of CNTF (21). According to the dose-response and time-course experiments, the maximal stimulation of CNTF on astrocytes was observed at $50 \mathrm{ng} / \mathrm{ml}$ and the 48 -h time-point (22). On this basis, the same concentration and time course were adopted in the present study to determine the activation of astrocytes induced by CNTF. To rule out the possible roles of exogenous CNTF in CNTF-ACM, astrocytes were rinsed with PBS 3 times following CNTF treatment. Subsequently, the cells were cultured with fresh serum-free DMEM medium for $48 \mathrm{~h}$ before ACM collection.

Compared to the level of $\left[\mathrm{Ca}^{2+}\right]_{\mathrm{i}}$ in the UT-ACM group, a stable increase was noticed in $\left[\mathrm{Ca}^{2+}\right]_{i}$ in cultured neurons from rat cortex treated by CNTF-ACM. This is consistent with our previous study, indicating that CNTF can upregulate the activity of L-type calcium channel in neurons (6). Additionally, the ELISA assay revealed that the concentration of FGF-2 in CNTF-ACM was increased markedly compared with that in UT-ACM, which were in accordance with previous 
studies $(23,24)$. Previously, CNTF contributed to the elevation of NGF in astrocytes (23); however, in the present study, no notable changes were observed in NGF content between CNTF-ACM and UT-ACM.

In the present study, the effects of $\alpha$ FGF-2, a FGF-2 monoclonal neutralizing antibody, was also investigated on the level of $\left[\mathrm{Ca}^{2+}\right]_{\mathrm{i}}$ in neurons. The results revealed that $\alpha \mathrm{FGF}-2$ could attenuate the increase of $\left[\mathrm{Ca}^{2+}\right]_{i}$ in neurons, which demonstrated that FGF-2 is responsible for the induction of $\left[\mathrm{Ca}^{2+}\right]_{i}$ by CNTF-ACM in neurons. Notably, $\alpha$ FGF-2 failed to block the effects of CNTF-ACM on $\left[\mathrm{Ca}^{2+}\right]_{i}$ completely, which may be associated with the presence of other active substances contained in CNTF-ACM. To date, several cytokines have been identified from cytokine-activated astrocytes, such as IL-1 $\beta$, glia-derived neurotrophic factor, neurotrophin-3, brain-derived neurotrophic factor, transforming growth factor- $\beta$, interferon- $\gamma$, as well as tumor necrosis factor- $\alpha$ (8). These cytokines may participate in the upregulation of $\left[\mathrm{Ca}^{2+}\right]_{\mathrm{i}}$ by CNTF-ACM in neurons.

In conclusion, the present results showed that CNTF-ACM induced an increase of the $\left[\mathrm{Ca}^{2+}\right]_{\mathrm{i}}$ in rat cortical neurons, which was partially attributable to the elevation of FGF-2 in CNTF-ACM. These findings provide a new insight into the indirect regulatory effects of CNTF on neuronal biological function through activating astrocytes.

\section{Acknowledgements}

The present study was supported by the National Natural Science Foundation of China (grant no. 81171117), the Doctor Point Foundation of Ministry of Education of China (grant no. 44) and the National Natural Science Foundation of Anhui Province (grant no. 1506c085014).

\section{References}

1. Adler R, Landa KB, Manthorpe M and Varon S: Cholinergic neuronotrophic factors: Intraocular distribution of trophic activity for ciliary neurons. Science 204: 1434-1436, 1979.

2. Askvig JM and Watt JA: The MAPK and PI3K pathways mediate CNTF-induced neuronal survival and process outgrowth in hypothalamic organotypic cultures. J Cell Commun Signal 9 : 217-231, 2015.

3. Chowdhury SR, Saleh A, Akude E, Smith DR, Morrow D, Tessler L, Calcutt NA and Fernyhough P: Ciliary neurotrophic factor reverses aberrant mitochondrial bioenergetics through the JAK/STAT pathway in cultured sensory neurons derived from streptozotocininduced diabetic rodents. Cell Mol Neurobiol 34: 643-649, 2014.

4. Vigneswara V, Akpan N, Berry M, Logan A, Troy CM and Ahmed Z: Combined suppression of CASP2 and CASP6 protects retinal ganglion cells from apoptosis and promotes axon regeneration through CNTF-mediated JAK/STAT signalling. Brain 137: 1656-1675, 2014.

5. Seidel JL, Faideau M, Aiba I, Pannasch U, Escartin C, Rouach N, Bonvento $\mathrm{G}$ and Shuttleworth $\mathrm{CW}$ : Ciliary neurotrophic factor (CNTF) activation of astrocytes decreases spreading depolarization susceptibility and increases potassium clearance. Glia 63: 91-103, 2015.

6. Wang X, Zheng H, Liu C, Zhu C, Wang W and Li Z: Ciliary neurotrophic factor-treated astrocyte conditioned medium regulates the L-type calcium channel activity in rat cortical neurons. Neurochem Res 33: 826-832, 2008.
7. Kajitani N, Hisaoka-Nakashima K, Morioka N, Okada-Tsuchioka M, Kaneko M, Kasai M, Shibasaki C, Nakata Y and Takebayashi M: Antidepressant acts on astrocytes leading to an increase in the expression of neurotrophic/growth factors: Differential regulation of FGF-2 by noradrenaline. PLoS One 7: e51197, 2012.

8. Liberto CM, Albrecht PJ, Herx LM, Yong VW and Levison SW: Pro-regenerative properties of cytokine-activated astrocytes. J Neurochem 89: 1092-1100, 2004

9. Katsuki H, Shitaka Y, Saito H and Matsuki N: A potential role of Ras-mediated signal transduction for the enhancement of depolarization-induced $\mathrm{Ca}^{2+}$ responses in hippocampal neurons by basic fibroblast growth factor. Brain Res Dev Brain Res 111: 169-176, 1998.

10. Yagami T, Takase K, Yamamoto Y, Ueda K, Takasu N, Okamura N, Sakaeda T and Fujimoto M: Fibroblast growth factor 2 induces apoptosis in the early primary culture of rat cortical neurons. Exp Cell Res 316: 2278-2290, 2010.

11. Hall KE, Sheng HC, Srinivasan S, Spitsbergen JM, Tuttle JB, Steers WD and Wiley JW: Treatment of aged rat sensory neurons in short-term, serum-free culture with nerve growth factor reverses the effect of aging on neurite outgrowth, calcium currents, and neuronal survival. Brain Res 888: 128-137, 2001.

12. Vivas O, Kruse M and Hille B: Nerve growth factor sensitizes adult sympathetic neurons to the proinflammatory peptide bradykinin. J Neurosci 34: 11959-11971, 2014.

13. McCarthy KD and de Vellis J: Preparation of separate astroglial and oligodendroglial cell cultures from rat cerebral tissue. J Cell Biol 85: 890-902, 1980.

14. Zsembery A, Boyce AT, Liang L, Peti-Peterdi J, Bell PD and Schwiebert EM: Sustained calcium entry through P2X nucleotide receptor channels in human airway epithelial cells. J Biol Chem 278: 13398-13408, 2003.

15. Ojeda SR, Ma YJ, Lee BJ and Prevot V: Glia-to-neuron signaling and the neuroendocrine control of female puberty. Recent Prog Horm Res 55: 197-224, 2000.

16. Lu X, Al-Aref R, Zhao D, Shen J, Yan Y and Gao Y: Astrocyteconditioned medium attenuates glutamate-induced apoptotic cell death in primary cultured spinal cord neurons of rats. Neurol Res 37: 803-808, 2015.

17. Taylor AR, Gifondorwa DJ, Newbern JM, Robinson MB, Strupe JL, Prevette D, Oppenheim RW and Milligan CE: Astrocyte and muscle-derived secreted factors differentially regulate motoneuron survival. J Neurosci 27: 634-644, 2007.

18. Kang SS, Keasey MP, Arnold SA, Reid R, Geralds J and Hagg T: Endogenous CNTF mediates stroke-induced adult CNS neurogenesis in mice. Neurobiol Dis 49: 68-78, 2013.

19. Watt JA, Bone S, Pressler M, Cranston HJ and Paden CM: Ciliary neurotrophic factor is expressed in the magnocellular neurosecretory system of the rat in vivo: Evidence for injuryand activity-induced upregulation. Exp Neurol 197: 206-214, 2006.

20. Ip NY, McClain J, Barrezueta NX, Aldrich TH, Pan L, Li Y, Wiegand SJ, Friedman B, Davis S and Yancopoulos GD: The alpha component of the CNTF receptor is required for signaling and defines potential CNTF targets in the adult and during development. Neuron 10: 89-102, 1993.

21. Rudge JS, Li Y, Pasnikowski EM, Mattsson K, Pan L, Yancopoulos GD, Wiegand SJ, Lindsay RM and Ip NY: Neurotrophic factor receptors and their signal transduction capabilities in rat astrocytes. Eur J Neurosci 6: 693-705, 1994.

22. Levison SW, Hudgins SN and Crawford JL: Ciliary neurotrophic factor stimulates nuclear hypertrophy and increases the GFAP content of cultured astrocytes. Brain Res 803: 189-193, 1998.

23. Albrecht PJ, Dahl JP, Stoltzfus OK, Levenson R and Levison SW: Ciliary neurotrophic factor activates spinal cord astrocytes, stimulating their production and release of fibroblast growth factor-2, to increase motor neuron survival. Exp Neurol 173: 46-62, 2002.

24. Albrecht PJ, Murtie JC, Ness JK, Redwine JM, Enterline JR, Armstrong RC and Levison SW: Astrocytes produce CNTF during the remyelination phase of viral-induced spinal cord demyelination to stimulate FGF-2 production. Neurobiol Dis 13: 89-101, 2003. 